\title{
ARTICLE OPEN \\ Single-cell analysis reveals individual spore responses to simulated space vacuum
}

\author{
Lin $\mathrm{He}^{1,2}$, Shiwei Wang ${ }^{3}$, Marta Cortesão ${ }^{4}$, Muying $\mathrm{Wu}^{1}$, Ralf Moeller ${ }^{4}$, Peter Setlow ${ }^{5}$ and Yong-qing $\mathrm{Li}^{1,2}$
}

Outer space is a challenging environment for all forms of life, and dormant spores of bacteria have been frequently used to study the survival of terrestrial life in a space journey. Previous work showed that outer space vacuum alone can kill bacterial spores. However, the responses and mechanisms of resistance of individual spores to space vacuum are unclear. Here, we examined spores' molecular changes under simulated space vacuum $\left(\sim 10^{-5} \mathrm{~Pa}\right)$ using micro-Raman spectroscopy and found that this vacuum did not cause significant denaturation of spore protein. Then, live-cell microscopy was developed to investigate the temporal events during germination, outgrowth, and growth of individual Bacillus spores. The results showed that after exposure to simulated space vacuum for 10 days, viability of spores of two Bacillus species was reduced up to $35 \%$, but all spores retained their large $\mathrm{Ca}^{2}$ ${ }^{+}$-dipicolinic acid depot. Some of the killed spores did not germinate, and the remaining germinated but did not proceed to vegetative growth. The vacuum treatment slowed spore germination, and changed average times of all major germination events. In addition, viable vacuum-treated spores exhibited much greater sensitivity than untreated spores to dry heat and hyperosmotic stress. Among spores' resistance mechanisms to high vacuum, DNA-protective $\alpha / \beta$-type small acid-soluble proteins, and nonhomologous end joining and base excision repair of DNA played the most important roles, especially against multiple cycles of vacuum treatment. Overall, these results give new insight into individual spore's responses to space vacuum and provide new techniques for microorganism analysis at the single-cell level.

npj Microgravity (2018)4:26 ; doi:10.1038/s41526-018-0059-7

\section{INTRODUCTION}

Can any terrestrial life survive in outer space? This question has long been of great interest in astrobiology because of the mystery of the origin of Earth's life and the dispersion of life in Universe. ${ }^{1,2}$ Outer space is an extremely challenging environment for all forms of terrestrial life, and is characterized by high vacuum, an intense radiation field of galactic and solar origin, extreme temperatures, and microgravity. ${ }^{1,2}$ Among these characteristics, water desorption due to high vacuum $\left(10^{-14}-10^{-4} \mathrm{~Pa}\right)$ is particularly notable, since water is one of the principal ingredients of cellular life and some water activity is indispensable for organismal growth. ${ }^{3}$ Thus the high vacuum conditions of outer space present a major challenge for any form of life, and only microorganisms in a dormant and resistant state might survive in outer space. That is why bacterial spores with their dormancy and extremely high resistance to harsh conditions are frequently used in astrobiology. ${ }^{4-9}$ One of the interests in astrobiology is whether living organisms can be transported between the planets of the Solar System by mechanisms such as on meteorites, and, if so, the surviving organisms must be highly resistant to the severe strain of a long journey through space. ${ }^{10,11}$ Dormant spores of bacteria are recognized as the hardiest known form of life on Earth and considerable effort has been invested in understanding the molecular mechanisms responsible for the extreme resistance of spores to harsh treatments. ${ }^{2}$ However, whether individual spores undergo severe molecular and morphological changes under space vacuum and how individual spores respond to space vacuum are not clear. It is also unclear whether individual spores exposed to space vacuum during a simulated space journey can return to the life when proper conditions are provided, and how rapidly the vacuum-exposed spores can do this. Consequently, knowledge about individual spore's responses to space conditions will help identify specific effects of space conditions on spores and address the question of possible transport of life through space as spores. $^{12}$

Bacterial spores are formed in sporulation by many Grampositive Bacilli and Clostridia, and are metabolically dormant. ${ }^{12-15}$ The return to life of such spores in germination has been the subject of significant research interest for four major reasons: (i) novel regulatory systems allow spores to remain in a dormant state for years and yet return to vegetative growth through germination and then outgrowth in minutes; (ii) spores have extremely high resistance to a wide variety of agents including high temperatures, desiccation, radiation, and toxic chemicals; (iii) spores of some species cause food spoilage and foodborne disease, as well as some serious human diseases, but after germination they lose their resistance properties and become relatively easy to kill; ${ }^{16-18}$ and (iv) spores have long been used as experimental organisms for astrobiology research, as their

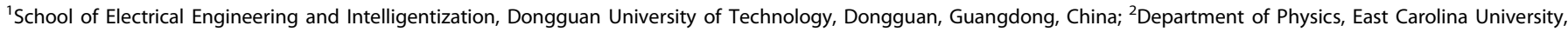

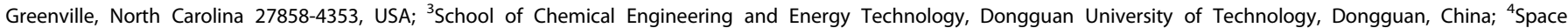

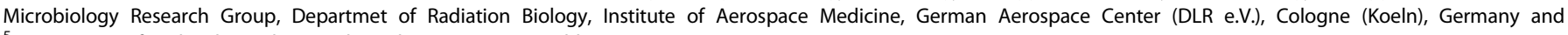
${ }^{5}$ Department of Molecular Biology and Biophysics, UConn Health, Farmington, Connecticut 06030-3305, USA

Correspondence: Y-q. Li (liy@ecu.edu)

These authors contributed equally: Lin He, Shiwei Wang
}

Received: 3 June 2018 Accepted: 23 October 2018

Published online: 04 December 2018 
extreme resistance may allow them to survive in the harsh environment of outer space. ${ }^{19}$

Many studies have found that spores exposed to various simulated space environments or in space when carried by balloons, rockets, or spacecraft can remain viable to some extent, provided they are shielded against the intense solar ultraviolet radiation. ${ }^{1,2,5,6}$ For example, it was found that wide-type $B$. subtilis spores survive up to $~ 70 \%$ after 10 days in space vaccum and there was still $1-2 \%$ viable spores after nearly six years in space. ${ }^{6}$ However, the germination and outgrowth of, and subsequent growth from, individual spores exposed to simulated space vacuum have not been studied. Notably, many simulated space parameters are used by the food industry to inactivate spores ${ }^{20,21}$ and vacuum treatment may be one method to either prevent spore germination and subsequent risk or accelerate spore germination in order to facilitate destruction of the much less resistant germinated spores.

Spore germination involves complex signal transduction pathways and biophysical events that have been studied best in spores of $B$. subtilis. ${ }^{14,22,23}$ Germination of $B$. subtilis spores can be triggered by $\mathrm{L}$-alanine or $\mathrm{L}$-valine or a combination of $\mathrm{L}$ asparagine, D-glucose, $\mathrm{D}$-fructose, and $\mathrm{K}^{+}$(AGFK) by interacting with specific nutrient germinant receptors (GRs) in the spore's inner membrane (IM), the GerA GR responding to L-alanine/Lvaline, and the GerB and GerK GRs responding to the AGFK mixture. ${ }^{14,18}$ There are also GR-independent germinants, including high hydrostatic pressure, a 1:1 chelate of $\mathrm{Ca}^{2+}$ with dipicolinic acid (CaDPA), and cationic surfactants, such as dodecylamine. ${ }^{14,22,23}$ During $B$. subtilis spore germination, several major events occur in a defined order. The earliest measurable event after germinant-GR interaction is termed commitment, in which even if the germinant is removed, committed spores continue through germination. ${ }^{23}$ Commitment is followed by release of monovalent cations $\left(\mathrm{H}^{+}, \mathrm{Na}^{+}\right.$, and $\left.\mathrm{K}^{+}\right)$, as well as the spore core's large pool ( $25 \%$ of spore core dry weight) of CaDPA, and its replacement by water. CaDPA release then triggers cortex-lytic enzymes to degrade spores' peptidoglycan (PG) cortex, and completion of cortex PG degradation allows the swelling and further hydration of the spore core. Once the core water content has increased to $\sim 80 \%$ of wet weight, equal to that in the growing cell, metabolism in the core begins, followed by macromolecular synthesis, spore elongation, and growth in the processes of outgrowth and then vegetative growth.

Normally, the process of an individual spore's germination is divided into four phases according to a spore's optical intensity in phase-contrast or differential interference contrast (DIC) microscopy, with the different phases begining or ending at times $T_{1}$, $T_{\text {lag, }} T_{\text {release, }}$ and $T_{\text {lys. }}{ }^{23-25} T_{1}$, also referred as $T_{\text {leakage, }}$ is the time when slow CaDPA leakage begins after germinant addition and is probably coincident with the time of commitment. $T_{\text {lag }}$ is the time when the initiation of very rapid CaDPA release begins after the start of slow CaDPA leakage, and $T_{\text {release }}$ is the time for completion of rapid CaDPA release. Following $T_{\text {release, }}$ there is a further small decline in spore refractility due to the hydrolysis of the spore cortex PG and spore core swelling and hydration; the time when spore refractility becomes constant is termed $T_{\text {lys }}$. These parameters, as well as $\Delta T_{\text {leakage }}=T_{\text {lag }}-T_{1}, \Delta T_{\text {release }}=T_{\text {release }}-T_{\text {lag }}$ and $\Delta T_{\text {lys }}=T_{\text {lys }}-T_{\text {release, }}$ are all major kinetic parameters of spore germination. After cortex PG hydrolysis, spores undergo outgrowth in which RNA, protein, and finally DNA are synthesized. As shown in this work, during this period, spores' length slowly increases to $\sim 1.5$-fold of that of dormant spores, and then the outgrowing spore emerges from the spore coat; at this time spore length decreases slightly. This latter time point is now designated as $T_{\text {elong. }}$.

Experiments using simulated space vacuum and in space have shown that high vacuum treatment for 1-10 days results in significant spore inactivation. ${ }^{1,5,6}$ Previous work has shown that the crucial event leading to spore inactivation by high vacuum is water desorption, which exerts a strong mechanical stress on the spore envelope, cortex, and membranes, and affects the structural integrity of macromolecules, such as lipids, proteins, and, probably most importantly, nucleic acids. ${ }^{7,26,27}$ However, individual spore's responses to space vacuum are unclear and several obvious questions about high vacuum-treated spores warrant further investigation, including: (i) do vacuum-killed spores, which cannot proceed to vegetative growth after high vacuum treatment, retain CaDPA; (ii) if they retain CaDPA, do vacuum-killed spores germinate when assessed by release of CaDPA and full hydration of the spore core; (iii) do germinated high vacuum-killed spores progress into outgrowth or cell elongation and cell division; (iv) is the germination, outgrowth, and vegetative growth of high vacuum-treated spores decreased and/or slowed as high vacuum treatment is extended; ( $v$ ) are resistance properties of spores surviving high vacuum treatment altered; and (vi) what spore features and components are most important in spore survival in high vacuum? In the current work, the viability and the kinetics of germination, outgrowth, elongation, and subsequent growth of and from hundreds of individual spores of Bacillus species exposed to simulated space vacuum (hereafter high vacuum) were investigated using Raman spectroscopy and live-cell differential interference contrast (DIC) microscopy. The effects of dry heat or high osmolarity on spores surviving high vacuum treatment was also examined. Finally, the roles of various spore protective components and DNA repair pathways in spore resistance to high vacuum were also determined. Taken together, the results of this study provide new insight into space vacuum effects on bacterial spores.

\section{RESULTS}

Spore viability and CaDPA content after high vacuum exposure After exposure to high vacuum for 1 or 10 days, the viability of $B$. subtilis PS533 (wild type) spores fell 25 and 36\%, respectively, compared to that of untreated spores (Fig. 1a). While the difference in viability between vacuum-treated and untreated spores was significant, the difference in spore viability after 1 and 10 days of vacuum exposure was not (Fig. 1a). A similar loss in viability after high vacuum exposure was also obtained with spores of another wild-type B. subtilis strain NCIB 3610 (Fig. 1a).

To observe the effects of high vacuum treatment on spore properties, laser tweezers Raman spectroscopy (LTRS) was used to compare the Raman spectra of $B$. subtilis spores given high vacuum treatment for 1 or 10 days and then suspended in water. The results showed that there were no obvious Raman spectral changes in spores of $B$. subtilis PS533 and NCIB 3610 suspended in water after high vacuum treatment, and spores of both strains had similar CaDPA levels before and after high vacuum treatment (Fig. $1 b)$. If multiple individual $B$. subtilis spores were directly examined under high vacuum by image-guided micro-Raman spectroscopy (Supplementary Fig. 1), all spores exposed to high vacuum for 1 day retained their CaDPA as expected. However, unexpectedly, intensities of Raman bands of CaDPA at 1017, 1397, 1450, and $1572 \mathrm{~cm}^{-1}$ were all slightly reduced, while the Raman band intensity at $1660 \mathrm{~cm}^{-1}$ due to protein was relatively unchanged, indicating that: (i) the spore core environment around CaDPA was changed under high vacuum (Fig. 1c) and (ii) there was minimal protein denaturation by high vacuum treatment. A similar result was obtained for B. cereus spores (Fig. 1d). Importantly, when high vacuum-treated spores were suspended in water, the Raman spectra of their CaDPA reverted to that of control spores. 
a

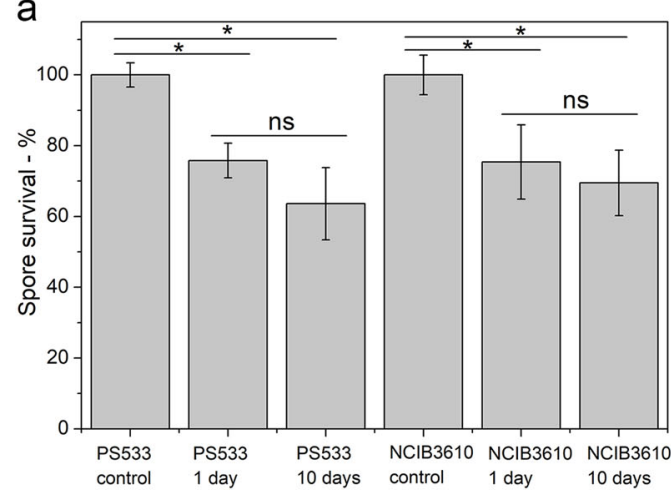

C

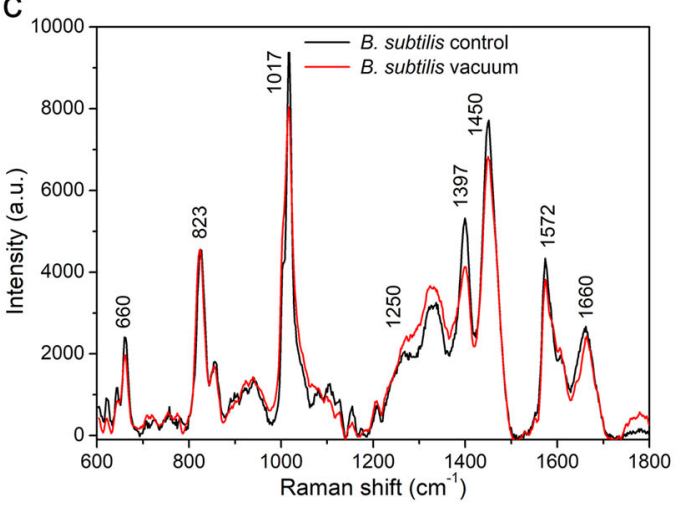

b

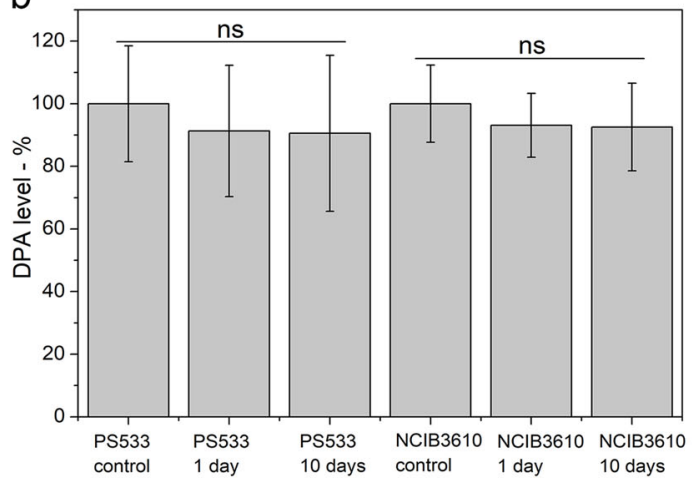

d

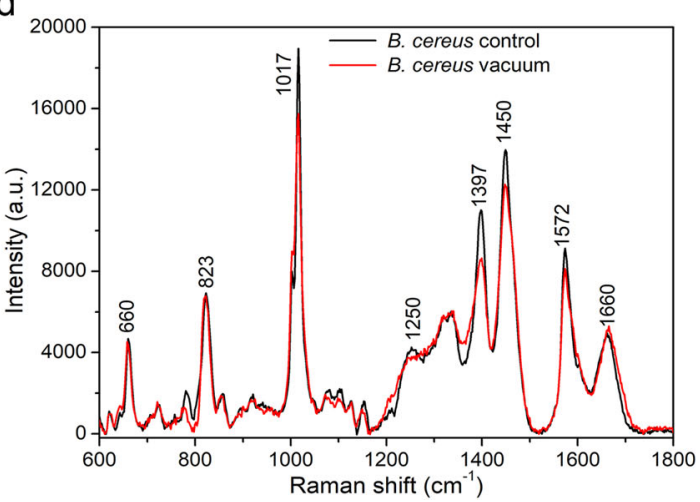

Fig. 1 Viability, DPA levels and Raman spectra of spores with and without high vacuum treatment. $\mathbf{a}$, $\mathbf{b}$ Viability of $B$. subtilis PS533 and NCIB 3610 spores that were exposed to high vacuum $\left(<2.6 \times 10^{-5} \mathrm{~Pa}\right)$ for various periods. Spores were first dried in a centrifuge tube and were exposed to high vacuum for 1 or 10 days. Spores that were dried in ambient laboratory pressure but not exposed to high vacuum are the control spores. After high vacuum exposure, spores were suspended in $100 \mathrm{uL}$ distilled water and cultured on LB plates at $37^{\circ} \mathrm{C}$, and spore viability was normalized to that of the control spores. C, d Average Raman spectra of multiple single spores of $B$. subtilis PS832 c and $B$. cereus $\mathbf{d}$ at atmospheric pressure $\left(1.0 \times 10^{5} \mathrm{~Pa}\right)$ (control) and high vacuum. The spectra of spores during the exposure to high vacuum were directly measured using image-guided micro-Raman spectroscopy. The laser power was $20 \mathrm{~mW}$ and integration time was $30 \mathrm{~s}$, and spectra shown were averaged over 30 individual spores. ${ }^{*} P<0.05 \%$; ns, no significance

Nutrient and non-nutrient germination of untreated and high vacuum-treated $B$. subtilis spores

Germination of $B$. subtilis spores can be triggered by GRdependent nutrient germinants such as L-valine or AGFK or GRindependent non-nutrient germinants, such as exogenous CaDPA or dodecylamine. In order to investigate the damage caused by high vacuum exposure to spores' germination, the germination of spore populations with all germinants noted above was examined. The results showed that high vacuum treatment for 1 or 10 days decreased rates of germination with all germinants, and decreased the percentages of germination with all germinants except CaDPA (Fig. 2a-d).

While the analysis of spore populations provided some information on the germination behavior of high vacuumtreated spores, these germination curves were the average behavior of many different spores whose individual behavior could differ due to intrinsic spore germination heterogeneity. ${ }^{14,22,23}$ Therefore, germination of multiple individual untreated and high vacuum-treated B. subtilis PS533 spores was also examined with the germinants mentioned above (Table 1; Supplementary Figs 2-5). Individual untreated spores germinated rapidly, most by $\sim 60$ min (Fig. 2), and the rapid CaDPA release for individual spores between $T_{\text {lag }}$ and $T_{\text {release }}$ took place almost in parallel (Supplementary Fig. 2a-5a); this was also true for spores high vacuum treated for 1 or 10 days (Supplementary Figs 2b,c-5b, c). However, the germination kinetics of multiple individual high vacuum-treated spores differed significantly from those of untreated spores and there were differences in the effects on germination with different germinants. In particular, with GRdependent germinants, the average values of $T_{1}, T_{\text {lag, }}, T_{\text {release, }}$ and $\Delta T_{\text {lys }}$ increased with high vacuum exposure, but $\Delta T_{\text {leakage }}$ and $\Delta T_{\text {release }}$ values were changed minimally (Table 1$)$. With the nonnutrient germinants CaDPA and dodecylamine, the results were more complex. Average values of $T_{1}$ and $T_{\text {lag }}$ in CaDPA and dodecylamine germination increased after high vacuum exposure. However, with CaDPA germination, as high vacuum exposure time increased, the $\Delta T_{\text {release }}$ times decreased, and the $\Delta T_{\text {lys }}$ times increased while $\Delta T_{\text {leakage }}$ times did not change. In contrast, with dodecylamine germination, as high vacuum exposure time increased, values of $\Delta T_{\text {leakage }}$ and $\Delta T_{\text {release }}$ values increased and those of $\Delta T_{\text {lys }}$ decreased (Table 1 ).

Comparison of germination, outgrowth, elongation, and subsequent growth from untreated and high vacuum-treated B. subtilis spores

In order to analyze the effects of high vacuum treatment on spore germination, outgrowth, elongation, and subsequent growth, spores of $B$. subtilis PS533 with and without high vacuum treatment were cultured on an LB medium agar pad on a microscope coverslip at $37^{\circ} \mathrm{C}$, and DIC images were recorded every $60 \mathrm{~s}$ (Fig. 3a, b). The results analyzing a single spore showed that when the untreated spore began rapid CaDPA release at $T_{\text {lag }}$ spore length increased slowly. Between the $T_{\text {lys }}$ and $T_{\text {elong }}$ time points, this spore initiated outgrowth, and spore length slowly 
a

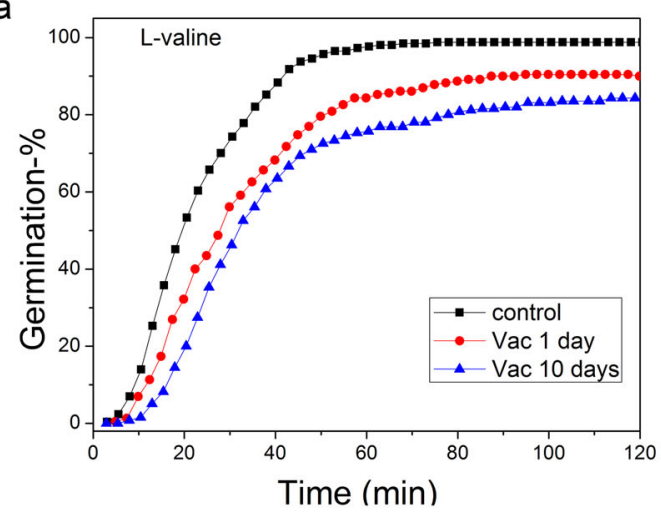

C

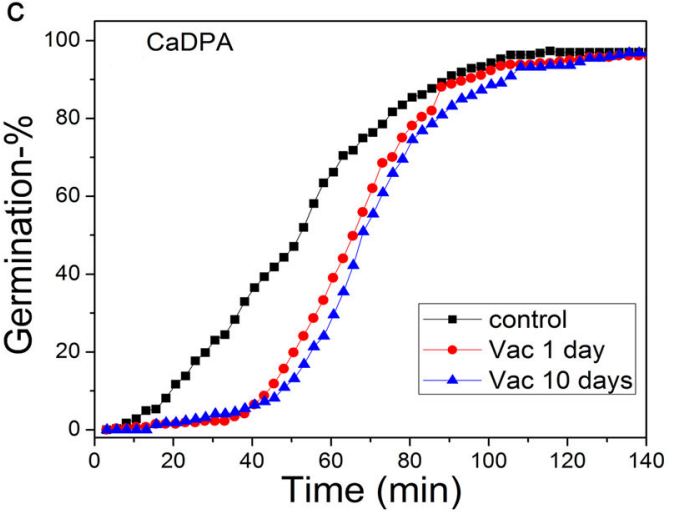

b

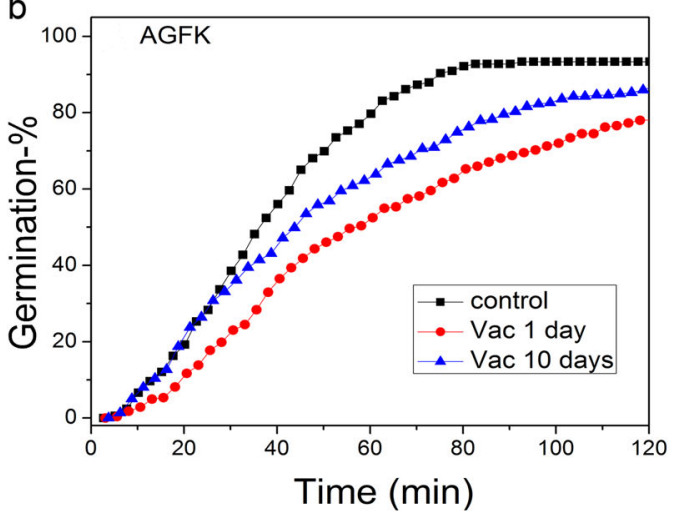

d

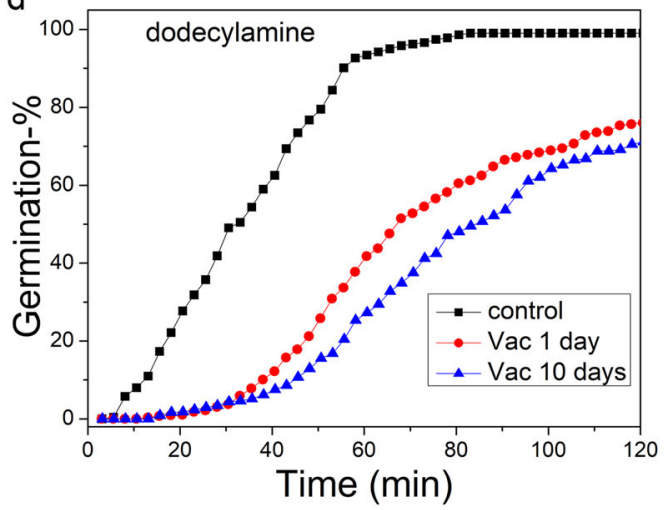

Fig. 2 Germination of Bacillus subtilis PS533 spores with and without high vacuum treatment. Spores without or with high vacuum treatment $\left(<2.6 \times 10^{-5} \mathrm{~Pa}\right)$ for 1 or 10 days were germinated with $1 \mathrm{mM} \mathrm{L}$-valine in $25 \mathrm{mM} \mathrm{K}$-Hepes (pH 7.4) at $37^{\circ} \mathrm{C} \mathrm{a}, 10 \mathrm{mM}$ AGFK in $25 \mathrm{mM} \mathrm{K}$-Hepes $\left(\mathrm{pH} 7.4\right.$ ) at $37^{\circ} \mathrm{C} \mathrm{b}, 60 \mathrm{mM} \mathrm{CaDPA}$ at $25^{\circ} \mathrm{C} \mathbf{c}$, and $1.0 \mathrm{mM}$ dodecylamine at $50^{\circ} \mathrm{C} \mathrm{d}$, and germination of 500 individual spores was assessed, all as described in Methods

Table 1. Mean values and standard deviations of $T_{1}, T_{\text {lag, }} T_{\text {release, }}$ and $\Delta T_{\text {release }}$ for germination of $B$. subtilis PS533 untreated and high vacuum-treated spores with different germinants ${ }^{\mathrm{a}}$

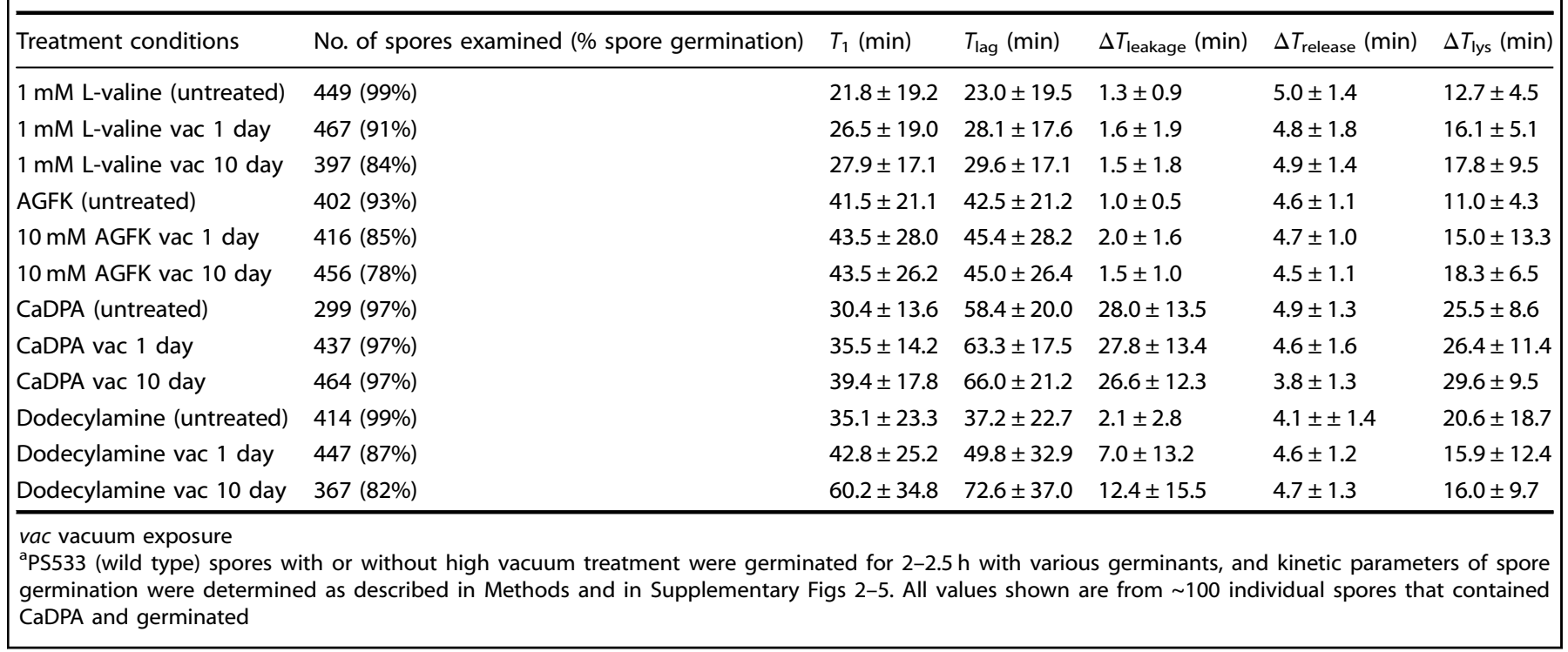

increased $\sim 1.5$-fold over that of the dormant spore. The new cell then emerged from the original spore coat, spore length decreased slightly at $\mathrm{T}_{\text {elong }}$ and, then cell length began increasing rapidly leading to the generation of a growing cell at $T_{2}$ (Fig. 3a, $\mathrm{C}$, $\mathrm{d}$; and see also Supplementary Movie 1). Perhaps the emergence of the outgrowing spore from the spore coat escapes the constraint of the coat on any increase in spore width. Similar phenomena were observed for germination, outgrowth, 


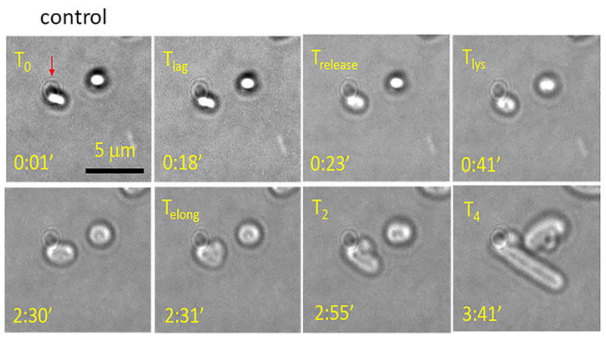

C

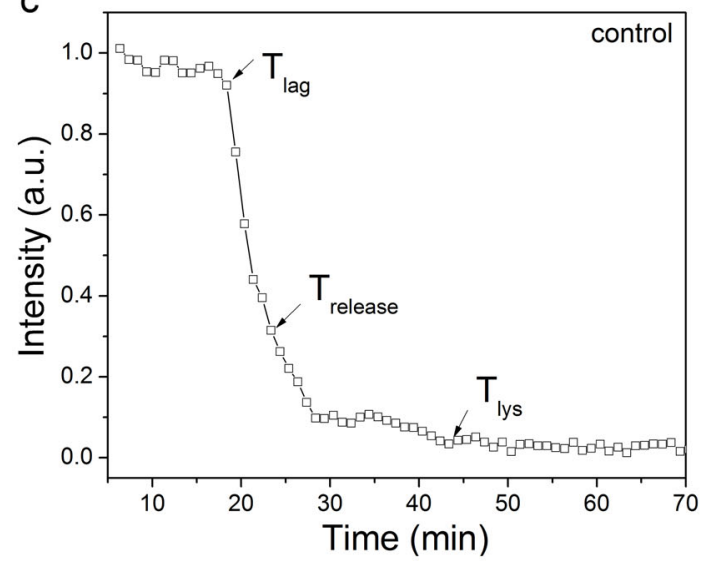

e

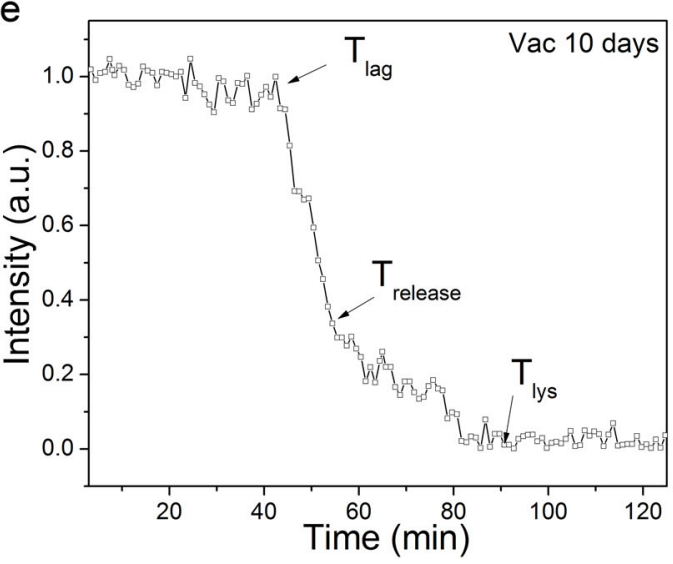

b

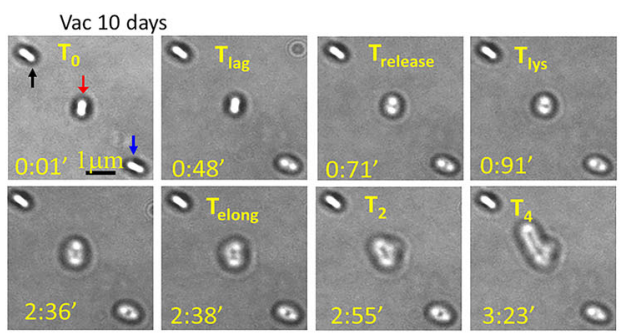

d

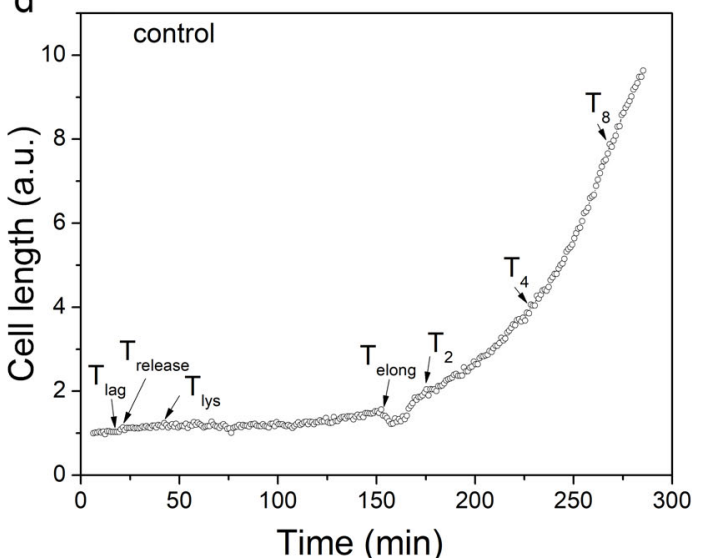

$f$

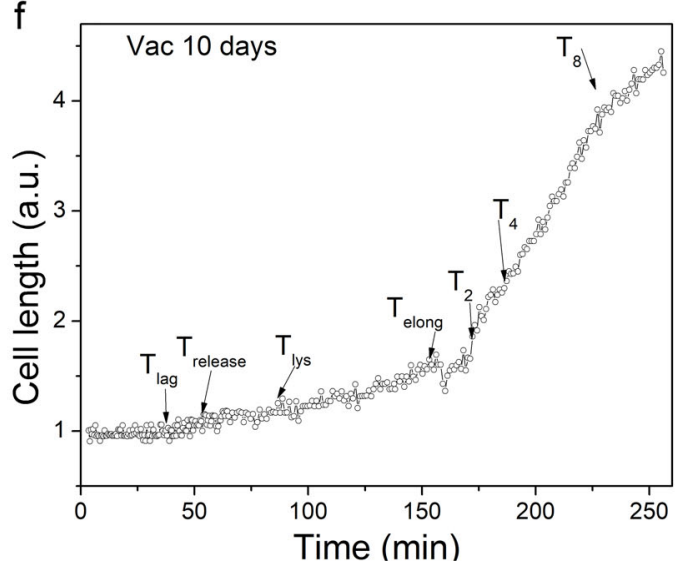

Fig. 3 Germination, outgrowth, elongation, and growth of individual PS533 spores without or with high vacuum treatment. Spores with or without a 10 day high vacuum treatment were incubated on an LB medium agar pad on a microscope coverslip at $37^{\circ} \mathrm{C}$ and spore and cell images were obtained by DIC microscopy as described in Methods. $\mathbf{a}$, $\mathbf{b}$ Cell images at various times. In the $0.01 \mathrm{~min}$ images, the red arrows in $\mathrm{a}$ and $\mathrm{b}$ indicate spores that germinated and ultimately grew, the black arrow in b indicates a spore that never germinated, and the blue arrow in (b) indicates a spore which germinated but did not grow. c, e Intensities of bright-field DIC images at various culture times; and $\mathbf{d}$, $\mathbf{f}$ spore/ cell length vs culture time

elongation, and subsequent growth of a single high vacuumtreated spore (Fig. 3b, e, f; and see Supplementary Movie 2). However, a number of high vacuum-treated spores germinated but did not undergo outgrowth and elongation, and did not give rise to growing cells (Fig. 3b). Presumably these are spores that were killed by the high vacuum treatment.

Analysis of the germination, outgrowth, elongation, and growth kinetics of multiple individual spores using phase-contrast microscopy gave similar results to those seen by DIC microscopy (Fig. $4 a$, b). Furthermore, comparison of the spore/cell length vs time curves of multiple germinated and growing spores without or with high vacuum exposure found that rates of cell length increase following $T_{2}$ exhibited no significant difference (compare Fig. 4c, d). However, while 34/35 of untreated spores germinated and grew by $240 \mathrm{~min}$, of the 57 high vacuum-treated spores observed, 4 did not germinate, and 8 germinated but did not initiate outgrowth and subsequent elongation and growth by $240 \mathrm{~min}$ (Fig. 4c, d). Thus $21 \%$ of high vacuum-treated spores appeared to be dead, a percentage not too different from that seen when viability of untreated and high vacuum-treated spores was compared (Fig. 2a).

Changes in spore stress resistance after high vacuum treatment Previous work has shown that spores surviving a number of inactivation treatments may be damaged and less able to resist an additional stress such as high heat or high salt levels in recovery media. $^{26,28}$ Notably, the temperature in outer space may change 

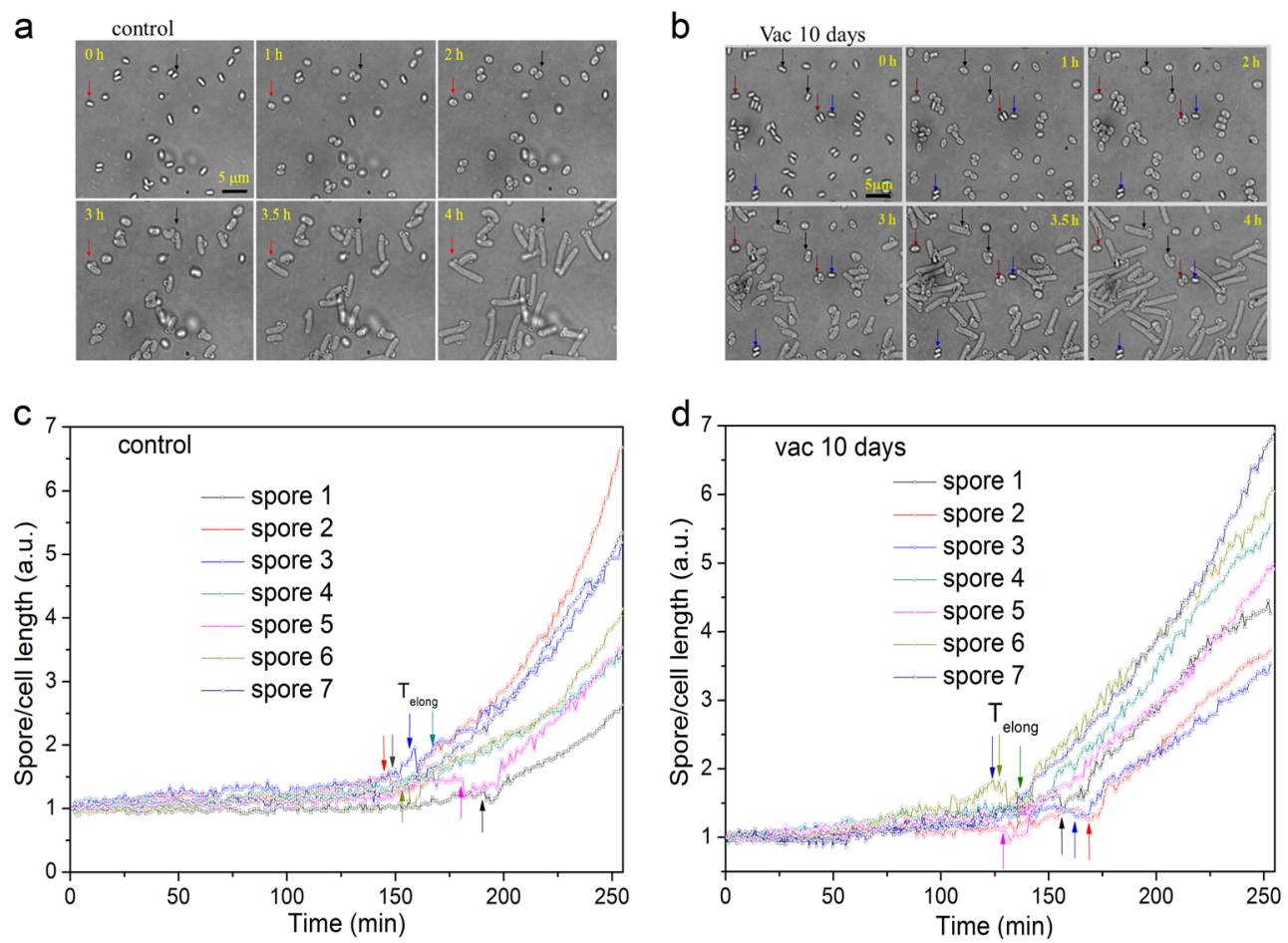

Fig. 4 Germination, outgrowth, elongation, and growth of multiple individual untreated B. subtilis PS533 spores without a, $\mathbf{c}$ or with $\mathbf{b}$, $\mathbf{d}$ a 10 day high vacuum treatment. Untreated or high vacuum-treated spores were cultured on an LB medium agar pad on a microscope coverslip at $37^{\circ} \mathrm{C}$ and bright-field images were recorded every $60 \mathrm{~s}$ for $4 \mathrm{~h}$ as described in Methods. a, b Bright-field images of individual spores at various culture times. In a panels the red and black arrows show images of two spores that germinated and grew; in panel $\mathbf{b}$ the blue, red, and black arrows show the images of spores that never germinated, germinated but did not grow, and germinated and grew, respectively. c, $\mathbf{d}$ Cell length vs time for 7 individual untreated and high vacuum-treated spores that germinated and grew, and arrows denote the $\mathrm{T}_{\mathrm{elong}}$ times

from very low to very high depending on the orientation to the sun and the albedo of the spacecraft, and this might impact spore survival. To examine the combined effects of high vacuum and high heat, untreated and high vacuum-treated spores were exposed to dry heat at $140^{\circ} \mathrm{C}$ for $7 \mathrm{~min}$. Analysis of these treated spores' germination and growth on an LB medium agar pad showed that the combination of high vacuum and dry heat did not affect spore germination appreciably (Fig. 5a, e). However, only $\sim 4 \%$ of the spores given both treatments exhibited growth (Fig. 5b, f). In contrast, $64 \%$ of spores given high vacuum treatment alone grew (Fig. 1a), while growth from untreated spores given the dry heat treatment was unaffected (Fig. 5b, e).

To further examine the resistance properties of spores surviving high vacuum exposure, germination, and growth of untreated and vacuum-treated spores was determined on an LB medium agar pad with or without $1 \mathrm{M} \mathrm{NaCl}$. The results showed that germination of high vacuum-treated spores was reduced only slightly on the high salt medium (Fig. $5 \mathrm{c}, \mathrm{g}$ ). While the growth of the untreated spores on the high salt medium was reduced to $83 \%$, the growth from high vacuum-treated spores was reduced to $17 \%$ on the high salt medium (Fig. $5 \mathrm{~d}, \mathrm{~h}$ ), in contrast to $64 \%$ of high vacuum-treated spores grew on low salt medium (Fig. 1a). This $\sim 4$-fold reduction in growth indicates that the high vacuumtreated spores are more sensitive to hyperosmotic stress. This salt sensitivity is consistent with damage to IM proteins or the IM itself by high vacuum. ${ }^{28}$ Taken together, the results indicate that the combination of high vacuum with either dry heat or hyperosmotic stress caused synergistic spore killing.

Spore structural properties and DNA repair involved in spore survival under high vacuum

Previous work has shown that high vacuum kills spores at least in part by DNA damage. ${ }^{2}$ In order to determine the significance of the factors protecting spores from high vacuum damage, possible spore protective factors, including different spore structures, core water, and DPA content, as well as DNA repair mechanisms, were systematically investigated using spores with alterations in these various factors (Fig. $6 a-c)$. This work showed that protection by the two major DNA-binding $\alpha / \beta$-type SASPs (SspA or SspB) played the most important role in protecting spores against high vacuum, with spores lacking both major proteins of this type, termed $\alpha^{-} \beta^{-}$spores, killed $\geq 99.9 \%$ by one high vacuum treatment. Indeed, even desiccation alone reduced $a^{-} \beta^{-}$spore viability $\sim 10$-fold as expected. ${ }^{2,18}$ However, the other major SASP, SspE, which is not bound to spore DNA, played a minimal role at best in spore DNA protection against desiccation and high vacuum. Other genes in which mutations decreased spore resistance to high vacuum included $d a c B$, mutation of which alters spore cortex structure and gives spores with an elevated core water content; $\cot E$, mutation of which eliminates assembly of the spore outer coat; and sleB spoVF mutations which give DPA-less spores, which are stable and have an elevated core water content; when this strain is sporulated with exogenous DPA, developing spores can take this up to levels close to that in wild-type spores. ${ }^{29}$ Notably, the decreased high vacuum resistance of sleB spoVF spores alone or with other mutations was increased significantly when sleB spoVF strains were sporulated with DPA. Combination of sspA $\operatorname{ssp} B$ mutations with $d a c B$, sle $B$ spoVF, or $\cot E$ mutations further reduced spore high vacuum resistance. Overall, the relative importance of various protective factors in spore high vacuum resistance was a/ $\beta$-type SASP » core water content $($ dac $B)>$ outer coat layer $(\cot E) \approx$ spore DPA content (sleB spoVF) (Fig. 6a-c).

With regards to the role of individual DNA repair pathways, Nfo and ExoA, apurinic/apyrimidinic endonucleases involved in the base excision repair pathway (BER), displayed the most significant 

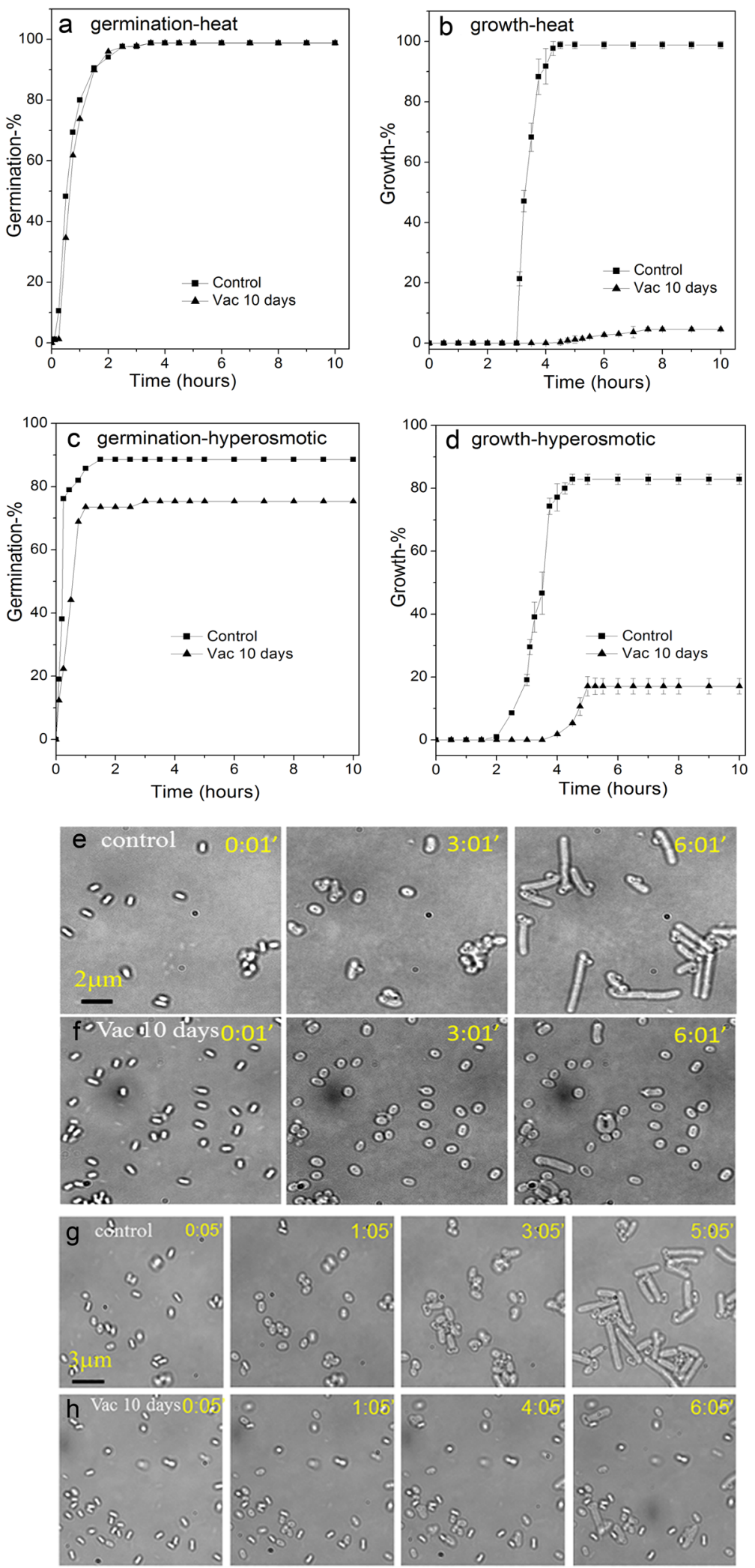

Fig. 5 Changes in spore resistance to dry heat or hyperosmotic stress after high vacuum treatment. The percentages of germination a, $\mathbf{c}$ and growth $\mathbf{b}$, $\mathbf{d}$ of multiple individual untreated (black box) or 10 day high vacuum-treated (black triangle) B. subtilis PS533 spores which were then treated with dry heat at $140^{\circ} \mathrm{C}$ for $7 \mathrm{~min} \mathbf{a}, \mathbf{b}$ and incubated at $37^{\circ} \mathrm{C}$ on either an LB medium agar pad, or not treated with dry heat but incubated at $37^{\circ} \mathrm{C}$ on an LB medium agar pad with $1 \mathrm{M} \mathrm{NaCl} \mathbf{c}$, d; the germination and growth of $>300$ individual spores was followed, all as described in Methods. Bright-field images were recorded every $60 \mathrm{~s}$ for $\sim 6 \mathrm{~h}$ for dry heat-treated $\mathbf{e}, \mathbf{f}$ and hyperosmotic cultures $\mathbf{g}$, $\mathbf{h}$ 

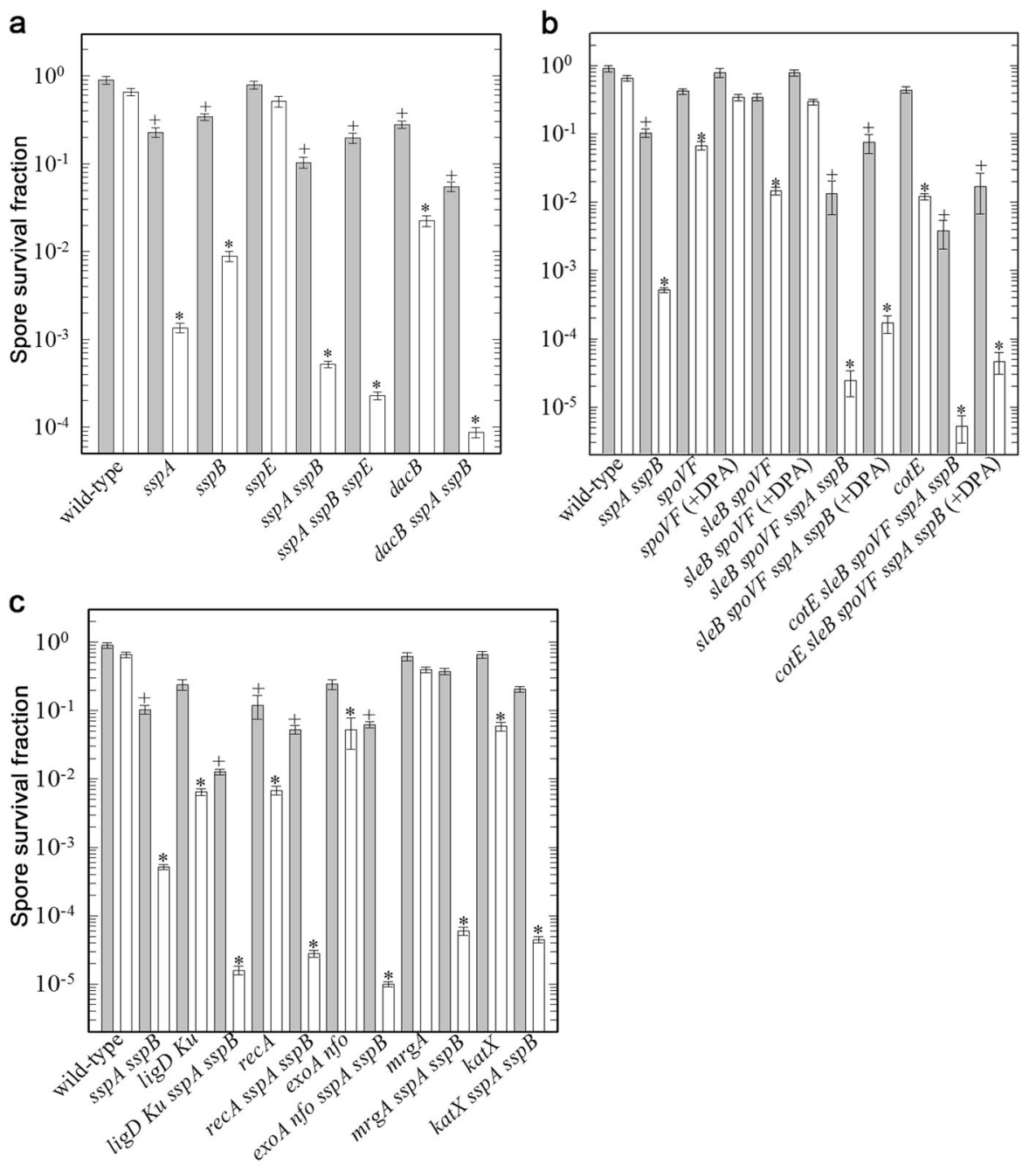

Fig. 6 High vacuum killing of $B$. subtilis spores with defects in spore structural components a, $\mathbf{b}$ or DNA repair (c). Spores of strain PS832 and its isogenic derivatives were exposed to high vacuum and spore survival was determined as described in Methods. The spore surviving fraction was determined from the ratio of $\mathrm{N} / \mathrm{N}_{0}$, with $\mathrm{N}_{0}$ the number of CFU of the untreated spores (spores stored dry in a laboratory desiccator) and $\mathrm{N}$ the high vacuum-treated spores. Values were analyzed in multigroup pairwise combinations, and differences with $P$ values of $<0.05$ were considered statistically significant. Gray bars, laboratory storage; white bars, high vacuum-treated spores. Plus, spore resistance to laboratory storage significantly different than the wild type; astereisk, spore resistance to high vacuum significantly different than the wild type

role, and the role of BER seemed greater than either homologous recombination repair mediated by RecA or non-homologous end joining (NHEJ) mediated by LigD Ku (Fig. 6c). The latter data suggest that the spectrum of high vacuum lesions in spore DNA includes more abasic sites than DNA strand breaks. ${ }^{19,30-32}$ Loss of the spore-specific catalase KatX had only a small effect on spore high vacuum resistance, and loss of the DNA-binding stress protein MrgA had no effect (Fig. 6c).

In order to further analyze the effects of the most important factor in spore protection against high vacuum, the major $\alpha / \beta$ type SASP, we examined the germination and outgrowth of individual $a^{-} \beta^{-}$spores given a high vacuum treatment (Fig. $\left.7 a, b\right)$. As noted above, the germination and growth of wild-type $B$. subtilis spores given a 10 day high vacuum treatment were reduced $23 \%$ and $33 \%$, respectively, compared to that of untreated spores (Fig. 7a, b). Notably, $a^{-} \beta^{-}$spore germination was minimally affected if at all by a 1 day high vacuum treatment, but none of these treated spores grew among 1000 observed spores (Fig. 7c, d and data not shown).
Effects of multiple cycles of high vacuum treatment on spore survival

While only limited inactivation (20-35\%) of spores of two wildtype Bacillus strains was obtained by 1-10 days of high vacuum treatment (Fig. 1), this was increased to $\sim 40 \%$ by three cycles of high vacuum and then atmospheric pressure (Fig. 8). Higher inactivation $(\sim 80 \%)$ was observed if spores were fully hydrated between high vacuum treatments (Supplementary Table 1). Given the significant killing of spores lacking DNA protection capacity, we also examined the killing of $\alpha^{-} \beta^{-} d a c B$ and $k a t X$ spores by multiple cycles of high vacuum treatment (Fig. 8). These experiments showed that two cycles of high vacuum treatment caused significantly more spore killing compared to one cycle, with three cycles of high vacuum treatment giving further significant killing. In addition, $a^{-} \beta^{-}$spores with additional defects in core water content $\left(\alpha^{-} \beta^{-} d a c B\right)$ or damage protection $\left(a^{-} \beta^{-}\right.$kat $X$ ) exhibited even more inactivation compared to spores with only single defects. Taken together, the results were consistent with our expectation that DNA protection would play 

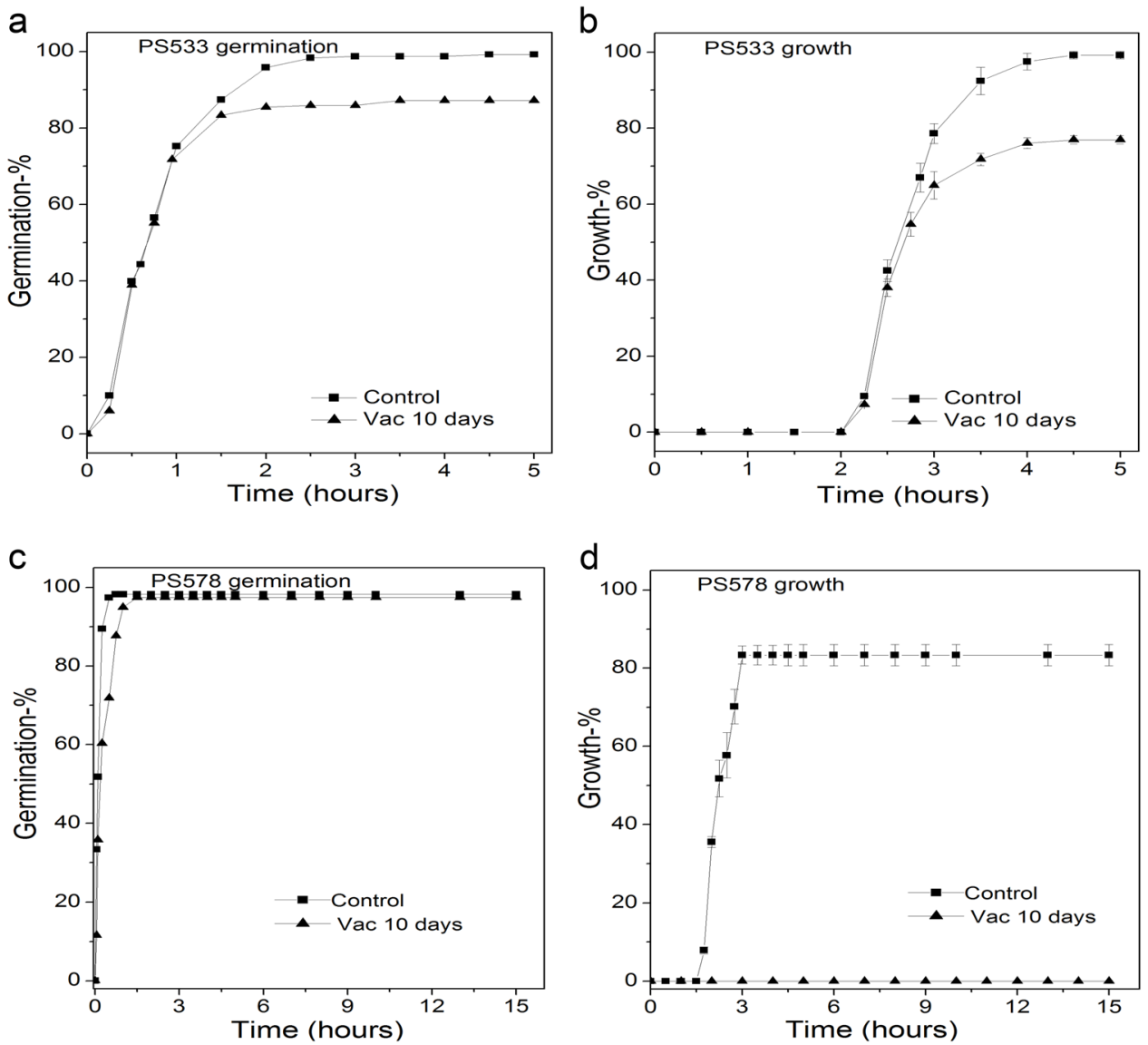

\section{e PS578 control}
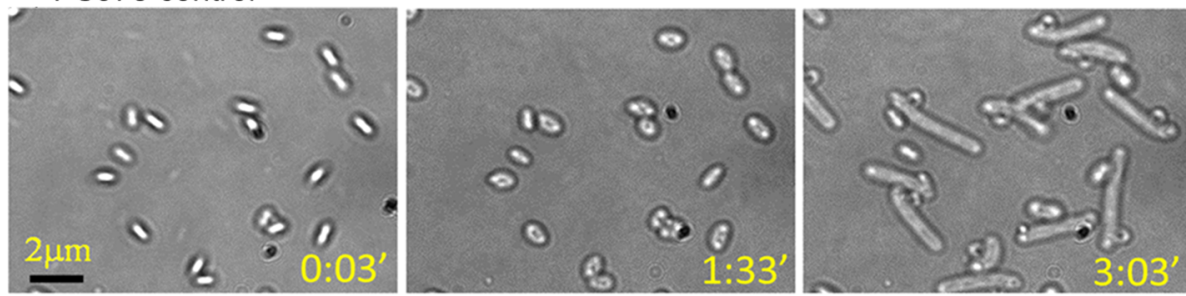

\section{f PS578 vac 10 days}
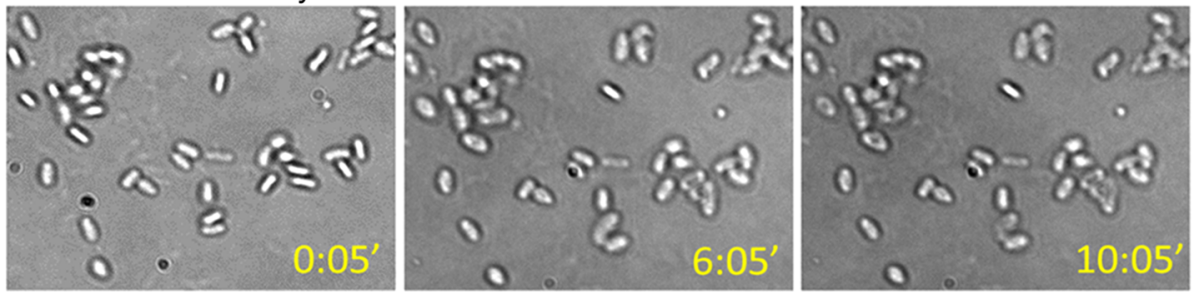

Fig. 7 Germination $\mathbf{a}, \mathbf{c}$ and growth $\mathbf{b}$, $\mathbf{d}$ of multiple individual untreated or high vacuum-treated B. subtilis PS533 (wild type) a, b or PS578 $\left(\alpha^{-} \beta^{-}\right)$c-f spores. B. subtilis PS533 or PS578 spores that were untreated (black square) or high vacuum-treated for 10 days (black triangle) were incubated on an LB medium agar pad at $37^{\circ} \mathrm{C}$ and the percentages of germination and growth of $\sim 500$ individual spores was determined, all as described in methods. Sequential bright-field images of individual PS578 spores without e or with $\mathbf{f}$ a 10-day high vacuum exposure were also obtained at various times

a significant role in defending spores against multiple cycles of high vacuum treatment.

\section{DISCUSSION}

Previous studies have found that when typical laboratory vacuum systems are used for drying or freeze-drying spores, wild-type
Bacillus spores exhibit no significant killing even under the conditions of prolonged desiccation or multiple cycles of freezedrying and rehydration. ${ }^{2}$ In contrast, previous work has shown that high vacuum equivalent to space vacuum does give significant spore killing. ${ }^{2}$ Notably, the current work indicated that high vacuum killing of spores appeared to be most dependent of the number of times spores were desiccated in high vacuum, and 


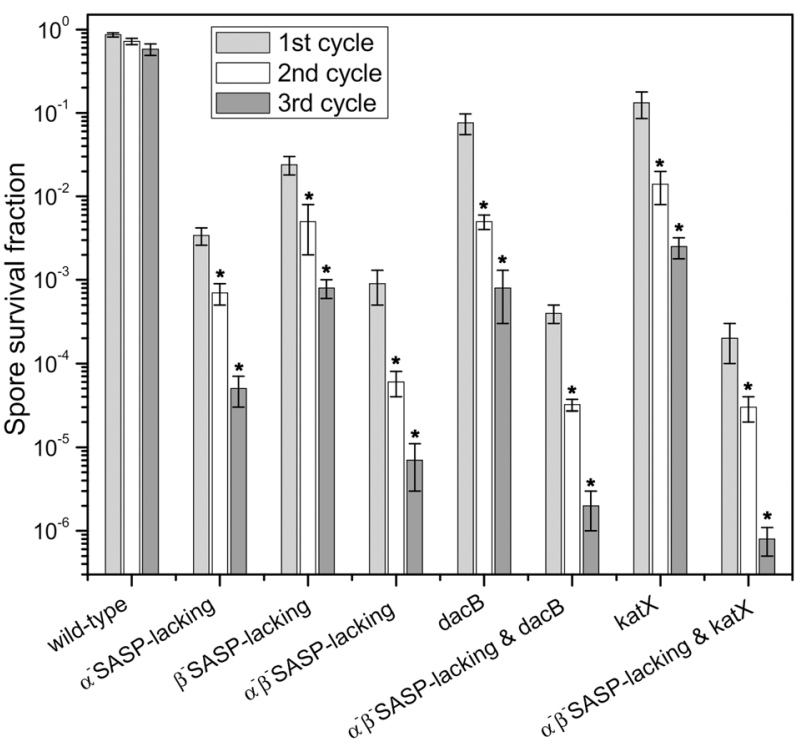

Genotype

Fig. 8 Killing of $B$. subtilis spores of different mutants by multiple cycles of high vacuum treatment. $B$. subtilis spores of different isogenic strains were exposed to high vacuum $\left(\sim 10^{-6} \mathrm{~Pa}\right)$ for $24 \mathrm{~h}$, followed by return to atmospheric pressure for $\sim 30 \mathrm{~min}$ before the next cycle of high vacuum treatment. Samples were $\sim 10^{8}$ spores immobilized on stainless steel discs, and CFU before and after each treatment were determined relative to CFU for control samples dried under ambient laboratory conditions. All experiments were conducted in triplicate, and standard deviations for all data are shown

less so on the actual residence time in high vacuum. This high vacuum had two notable effects on spores: (1) killing some spores; and (2) decreasing some spores' germination with various germinants. Obvious questions about these effects are how high vacuum treatment: (i) kills spores; and (ii) decreases spore germination. The results obtained in the current work confirm that high vacuum treatment kills spores largely by DNA damage. The evidence for this conclusion is as follows. (1) Spore killing by high vacuum is not by: (i) rupture of spores' inner membrane permeability barrier, since the dead spores retained CaDPA; (ii) massive protein denaturation, since this was not seen by Raman microspectrscopy, although this by no means rules out selective inactivation of a small number of crucial spore proteins as a cause for spore killing by high vacuum; and (iii) destruction of the ability to germinate, since dead spores still germinated and did not lyse, although the dead germinated spores never grew. (2) The fact that spore killing by high vacuum was greatly increased by a number of mutations that eliminate repair of different DNA lesions and by various pathways, including $\operatorname{rec} A$, lig $D k u$, and exo $A$ nfo strongly suggests that DNA damage is the major mechanism whereby high vacuum kills spores. However, the precise damage generated by high vacuum in spore DNA is not clear, and may include not only single and double strand breaks, but also some base loss as well, all as indicated by the effects of loss of different DNA repair genes on spore high vacuum sensitivity. Presumably, detailed analysis of DNA from high vacuum-killed spores could determine the types and amounts of specific damage.

The results of experiments examining effects of mutations in other than DNA repair genes on spore high vacuum sensitivity strongly indicated that the $\alpha / \beta$-type SASP, either SASP- $\beta$, more so SASP- $a$, and most of all both of these two major $\alpha / \beta$-type SASP played the most important role in high vacuum resistance of spores. This is consistent with the known protection of spore DNA by $a / \beta$-type SASP against damage by wet and dry heat, desiccation, oxidative damage, and UV and $\gamma$-radiation. ${ }^{2,33}$ While a/ $\beta$-type SASP play an important role in protection of spore DNA, and thus spore viability against high vacuum treatment, all the dead SASP-less spores germinated relatively normally, strongly suggesting that normal DNA function is not needed for completion of spore germination, including cortex PG hydrolysis. However, a number of other mutations affecting spore properties decreased spore resistance to high vacuum. Two, dacB or sleB spoVF mutations, result in spores with elevated core water content, the sleB spoVF double mutation by eliminating CaDPA in the spore, and the effects of this double mutation were almost eliminated by its sporulation with DPA which almost certainly reduced these spores core water content to close to that of wildtype spores. ${ }^{29}$ However, it is not clear why an elevated core water content would sensitize spores to high vacuum. One possibility is that while DNA in wild-type spores is all almost certainly in an Alike conformation due to $\alpha / \beta$-type SASP binding ${ }^{18}$ in $d a c B$ or sle $B$ spoVF spores with elevated core water some $\alpha / \beta$-type SASP might dissociate from DNA giving B-DNA, and perhaps the effects of complete water removal under high vacuum are more damaging to B-DNA than A-like DNA. Again it might be informative to examine the specific DNA damage in high vacuum-treated dacB and sleB spoVF spores. In addition, a higher core water content alone might lead to differences in the conformation of specific core molecules like DNA, and thus these moelcules susceptibility to deleterious effects of high vacuum.

There are also some minor decreases in spores' high vacuum resistance upon loss of the: (i) spores' outer coat in cotE spores; (ii) spore-specific catalase KatX; and (iii) and the oxidative stress resistance DNA-binding protein MrgA. One common characteristic of at least two of these mutations, $\cot E$ and $k a t X$, is that they greatly sensitize spores to some oxidizing agents, either as dormant or germinated spores, ${ }^{18,34}$ although the effects of oxidizing agents on germinating $m r g A$ spores has not been examined. Perhaps high vacuum treatment, either its imposition or removal, results in generation of oxidizing species that gain access to the dormant spore core in cotE spores, or into germinating katX spores, and thus can cause lethal damage to DNA or some other spore component. Again, as noted above, it could be informative to examine the DNA damage in high vacuum-killed cotE and katX spores.

As seen previously with dry heat- or wet heat-killed spores, ${ }^{20,35,36}$ after high vacuum exposure non-viable spores also retained CaDPA and did not release CaDPA upon suspension in water. These results indicate that high vacuum treatment does minimal damage to spores' IM permeability barrier that retains CaDPA. Indeed, multiple lines of evidence have shown that high vacuum inactivates spores by water desorption. ${ }^{7,27}$ The rates and extents of germination of high vacuum-treated spores with nutrient or non-nutrient germinants were all decreased somewhat compared to that of untreated spores, except for CaDPA germination. The fact that germination of high vacuum-treated spores via GR-dependent germinants in spores' IM as well as dodecylamine germination by activation of the SpoVA protein channel for CaDPA release, also in spores' IM, were slowed only slightly makes it extremely difficult to ascribe these changes to damage in specific spore proteins. This damage could also be in spores' IM itself where GRs and the SpoVA channel for CaDPA are located or in one or more IM proteins. Indeed, the salt sensitivity of high vacuum-treated spores is consistent with IM damage since spore treatment with oxidizing agents can cause salt sensitivity of outgrowing spores, and these treated spores also become heat sensitive. ${ }^{28}$ However, it is clear that damage to the germination apparatus alone is not how high vacuum kills spores.

Finally, it is notable that there was no detectable outgrowth of high vacuum-killed spores, just as seen recently with dry heatkilled $B$. subtilis spores. ${ }^{35,36}$ This may be significant from an applied perspective, since if high vacuum-killed spores don't outgrow, 
Table 2. B. subtilis strains used in this study ${ }^{a}$

\begin{tabular}{|c|c|c|}
\hline $\begin{array}{l}\text { Strain } \\
\text { number }\end{array}$ & Genotype & Phenotype \\
\hline NCIB3610 & Wild type & ref. $^{31}$ \\
\hline PS832 & Wild type & Laboratory 168 strain \\
\hline PS533 & Wild type & ref. $^{35}$ \\
\hline PS578 & $\operatorname{ssp} A s s p B$ & $\alpha^{-} \beta^{-}$ \\
\hline PS283 & $\operatorname{ssp} A$ & Lacking the $\alpha / \beta$-type SASP SspA \\
\hline PS338 & $s s p B$ & Lacking the $\alpha / \beta$-type SASP SspB \\
\hline PS355 & $\operatorname{ssp} A \operatorname{ssp} B$ & $\alpha^{-} \beta^{-}$ \\
\hline PS483 & $s s p E$ & Lacking the $\gamma$-type SASP SspE, $\gamma^{-}$ \\
\hline PS482 & $\operatorname{ssp} A \operatorname{ssp} B$ & $\alpha^{-} \beta^{-} \gamma^{-}$ \\
\hline PS1899 & $d a c B$ & Increased spore core water content \\
\hline PS2211 & $d a c B \operatorname{ssp} A s s p B$ & $\begin{array}{l}\text { Increased spore core water content, } \\
\alpha^{-} \beta^{-}\end{array}$ \\
\hline FB122 & sleB spoVF & No spore CaDPA \\
\hline FB122 (+DPA) & sleB spoVF & $\begin{array}{l}\text { Some spore CaDPA (sporulation } \\
\text { with DPA) }\end{array}$ \\
\hline PS3664 & $\begin{array}{l}\text { sleB spoVF sspA } \\
\text { ssp } B\end{array}$ & No spore CaDPA and $\alpha^{-} \beta^{-}$ \\
\hline $\begin{array}{l}\text { PS3664 } \\
(+D P A)\end{array}$ & $\begin{array}{l}\text { sleB spoVf sspA } \\
\text { ssp } B\end{array}$ & $\begin{array}{l}\text { Some spore CaDPA (sporulation } \\
\text { with DPA), } \alpha^{-} \beta^{-}\end{array}$ \\
\hline PS3722 & $\operatorname{ligD~Ku}$ & $\begin{array}{l}\text { Non-homologous DNA end joining } \\
\text { defect }\end{array}$ \\
\hline PS3751 & $\operatorname{lig} D K u \operatorname{ssp} A \operatorname{ssp} B$ & $\begin{array}{l}\text { Non-homologous end DNA joining } \\
\text { defect, } \alpha^{-} \beta^{-}\end{array}$ \\
\hline PERM454 & exoA nfo & $\begin{array}{l}\text { Apurinic/apyrimidinic } \\
\text { endonucleases defect }\end{array}$ \\
\hline PERM450 & $\begin{array}{l}\text { exoA nfo sspA } \\
\text { ssp } B\end{array}$ & $\begin{array}{l}\text { Apurinic/apyrimidinic } \\
\text { endonucleases defect, } \alpha^{-} \beta^{-}\end{array}$ \\
\hline PS2496 & $m r g A$ & DNA-binding stress protein defect \\
\hline PS2507 & $m r g A s s p A s s p B$ & DNA-binding stress protein, $\alpha^{-} \beta^{-}$ \\
\hline PS2558 & katX & Lacks spore catalase \\
\hline PS2559 & $\begin{array}{l}\text { katX sspA sspA } \\
\operatorname{ssp} B\end{array}$ & Lacks spore catalase, $\alpha^{-} \beta^{-}$ \\
\hline PS2318 & recA & $\begin{array}{l}\text { Homologous recombination, DNA } \\
\text { repair defects }\end{array}$ \\
\hline PS2319 & $\operatorname{rec} A \operatorname{ssp} A \operatorname{ssp} B$ & $\begin{array}{l}\text { Homologous recombination and } \\
\text { DNA repair defects, } \alpha^{-} \beta^{-}\end{array}$ \\
\hline AD28 & $\cot E$ & Spores lack outer coat \\
\hline PS3747 & $\begin{array}{l}\text { cotE sleB spoVF } \\
\text { sspA sspB }\end{array}$ & $\begin{array}{l}\text { No spore CaDPA, spores lack outer } \\
\text { coat, } \alpha^{-} \beta^{-}\end{array}$ \\
\hline $\begin{array}{l}\text { PS3747 } \\
(+D P A)\end{array}$ & $\begin{array}{l}\text { cotE sleB spoVF } \\
\text { sspA sspB }\end{array}$ & $\begin{array}{l}\text { Some spore CaDPA, no spore outer } \\
\text { coat, } \alpha^{-} \beta^{-} \text {(sporulated with DPA) }\end{array}$ \\
\hline
\end{tabular}

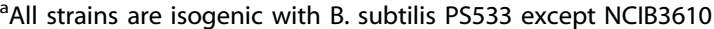

they will thus likely not synthesize any proteins. This could be especially important with spores from pathogenic bacteria, such as B. anthracis and Clostrdium botulium.

\section{MATERIALS AND METHODS}

Strains, media, and spore preparation

B. subtilis strains used in this study are listed in Table 2. B. cereus $T$ was originally obtained from $\mathrm{H}$. O. Halvorson. Spores of $B$. subtilis strains were prepared at $37^{\circ} \mathrm{C}$ on double strength Schaeffer's ( $2 \times \mathrm{SG}$ ) medium agar plates and $B$. cereus spores were also prepared on plates, all as described previously. ${ }^{35-37}$ All purified spores were stored at $4{ }^{\circ} \mathrm{C}$ in water protected from light and were $>98 \%$ free from growing or sporulating cells, germinated spores and cell debris as was observed by phase-contrast microscopy. In some experiments, B. subtilis sleB spoVF spores that make stable DPA-less spores were sporulated on plates with $100 \mu \mathrm{g} / \mathrm{ml}$ DPA. While sleB spoVF spores prepared without DPA in the sporulation medium have $\leq 1 \%$ of CaDPA levels of wild-type spores, when this strain is sporulated with $100 \mathrm{mg} / \mathrm{ml}$ DPA this gives spores that contain $~ 85 \%$ of the CaDPA level in wild-type spore. ${ }^{29}$

Image-guided multifocus confocal Raman micro-spectroscopy of individual spores in a high vacuum

To explore possible molecular changes in spores under high vacuum, a special vacuum chamber was developed (Supplementary Fig. 1), which allows direct observation of individual spores under high vacuum using image-guided single-cell confocal Raman micro-spectroscopy. ${ }^{38,39}$ Briefly, the spores $\left(\sim 1 \mu \mathrm{l}\right.$ of $10^{8}$ spores $/ \mathrm{ml}$ in water) were air dried on a quartz coverslip ( $0.1 \mathrm{~mm}$ thick) that was sealed on a window of a vacuum chamber pumped with a Turbo pumping station (Pfeiffer Vacuum, Berlin, Germany). The bright-field or phase-contrast image of multiple individual spores adhered in random positions on the quartz coverslip was recorded with an imaging camera, and then analyzed by a MATLAB program to locate their centroid positions in a field of view. These coordinates were used to drive a pair of galvo-mirrors and steer a single laser beam to illuminate the individual spores located. Confocal micro-Raman spectroscopy of the illuminated spores was recorded by a multichannel chargecoupled device (CCD) spectrometer (Princeton Instruments, PIXIS 400BR).

High vacuum treatment and measurement of spore viability and CaDPA content

High vacuum $\left(<2.6 \times 10^{-5} \mathrm{~Pa}\right)$ was routinely achieved in a vacuum chamber (Supplementary Fig. 1) pumped by a Turbo pumping station and a Turbo molecular pump (Pfeiffer Vacuum, Berlin, Germany). Spores $\left(\sim 1 \mu \mathrm{l}\right.$ of $\sim 10^{8}$ spores $/ \mathrm{ml}$ in water) in a centrifuge tube were placed inside the vacuum chamber to simulate space vacuum treatment. It took $\sim 2 \mathrm{~min}$ for the vacuum chamber to drop from atmospheric pressure to high vacuum by using an isolation valve. In order to be comparable with previous research, ${ }^{1,6}$ spores were exposed to high vacuum for 1 or 10 days. After the high vacuum treatment, the spores were suspended in distilled water to a concentration of $\sim 10^{7}$ spores $/ \mathrm{ml}$ and examined by laser tweezers Raman spectroscopy (LTRS) as described previously. ${ }^{40-42}$

To investigate effects of multiple cycles of high vacuum treatment on spore survival, $B$. subtilis spores of different strains were exposed to high vacuum $\left(\sim 2.3 \times 10^{-6} \mathrm{~Pa}\right)$ for 1 day in each cycle, followed by return to atmospheric pressure (in $\sim 10 \mathrm{~s}$ ) for $\sim 30 \mathrm{~min}$ before the next cycle of high vacuum treatment. In one experiment spores were suspended in water after each high vacuum treatment, and then redried prior to the next high vacuum treatment. Samples were air-dried spore monolayers $\left(1 \times 10^{8}\right.$ spores) immobilized on stainless steel discs. ${ }^{29}$ To recover spores from the discs, the spore monolayers were covered by a $10 \%$ aqueous polyvinyl alcohol solution (PVA) and after drying the spore-PVA layer was removed as described, ${ }^{2}$ and was suspended in $1 \mathrm{ml}$ of sterile distilled water, resulting in $>95 \%$ recovery of the spores. This procedure has no geno- or cytotoxic effect on spore viability. ${ }^{43}$ The CFU before and after each treatment were determined. In brief, the viability of control and high vacuum-treated spores suspended in water as described above was determined by serial dilution of samples in water, and application of aliquots to LB medium plates which were incubated at $37^{\circ} \mathrm{C}$ for 24 to $36 \mathrm{~h}$

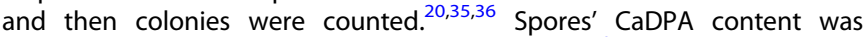
measured using LTRS as previously described. ${ }^{40,41}$ Individual spores suspended in water were randomly trapped by a 780-nm laser beam, and Raman scattering excited by the same laser beam was acquired by a CCD. CaDPA levels in individual trapped spores were determined from the intensity of the CaDPA-specific Raman band at $1,017 \mathrm{~cm}^{-1}$ relative to that of CaDPA standards.

Time-lapse differential interference contrast (DIC) microscopy monitoring of individual spore's germination

Spore germination was carried out with different types and concentrations of nutrient and non-nutrient germinants, including: (i) $1 \mathrm{mM} \mathrm{L}$-valine in 25 $\mathrm{mM} \mathrm{K-HEPES} \mathrm{buffer} \mathrm{(pH} \mathrm{7.4)} \mathrm{at} 37^{\circ} \mathrm{C}$; (ii) $10 \mathrm{mM}$ AGFK (10 mM each of Lasparagine, D-glucose, D-fructose, and $\mathrm{K}^{+}$) in $25 \mathrm{mM} \mathrm{K-HEPES}$ buffer ( $\mathrm{pH}$ 7.4) at $37^{\circ} \mathrm{C}$; (iii) $50 \mathrm{mM} \mathrm{CaDPA}(\mathrm{pH} 7.5$ ) at room temperature; or (iv) $1.0 \mathrm{mM}$ dodecylamine in $25 \mathrm{mM}$ K-HEPES buffer $\left(\mathrm{pH} \mathrm{7.4)}\right.$ at $50^{\circ} \mathrm{C}$. Heat 
activation of spores in water was carried out at $70^{\circ} \mathrm{C}$ for $30 \mathrm{~min}$ followed by placing on ice for $>15$ min prior to L-valine- and AGFK-germination experiments, but this is not needed for CaDPA and dodecylamine germination. $^{23}$

Analysis of the germination of multiple individual spores by DIC microscopy was as described previously. ${ }^{44,45}$ In brief, spores ( 1 $\mu$ l of $\sim 10^{7}-10^{8}$ spores $/ \mathrm{ml}$ in water) were spread on the surface of a microscope coverslip that was then dried in a vacuum desiccator for 5 to $10 \mathrm{~min}$. The coverslip was then mounted on and sealed to a microscope sample holder kept at a constant temperature. After adding preheated germinant solution to spores on the coverslips, a digital CCD camera (12 bits, 1392 by 1040 pixels) was used to record DIC images at a rate of 1 frame every $15 \mathrm{~s}$ for 120 to $180 \mathrm{~min}$. The analysis of DIC images was performed using a program written in Matlab to locate each spore's position and to calculate the averaged pixel intensity of an area with a 20 pixel diameter that covered the whole individual spore on a DIC image. The DIC image intensity of each individual spore was plotted as a function of the incubation time with a resolution of $15 \mathrm{~s}$. The initial intensity at $T_{0}$ was normalized to 1, and the intensity at the end of measurements was normalized to zero. From the time-lapse DIC image intensity, we can determine the time of completion of the rapid fall of $\sim 75 \%$ in a spore's DIC image intensity, consistent with the period of release of almost all of a spore's CaDPA; the end of this period is defined as $T_{\text {release, }}$ as confirmed by LTRS. $^{44}$ CaDPA release and spore cortex PG hydrolysis kinetics during the germination of individual spores are described by a number of parameters as described previously. ${ }^{23,24}$

Live-cell imaging of germination, outgrowth, and elongation and growth of single spores incubated on LB agar

For analysis of the germination, outgrowth, elongation, and subsequent vegetative growth of untreated or high vacuum-treated spores, aliquots of spores in water were applied to microscope slides, which were dried under low vacuum, and slides were mounted on a microscope sample holder kept at $37^{\circ} \mathrm{C}$, all as described above. Approximately $250 \mu \mathrm{L}$ of melted LuriaBertani $(\mathrm{LB})^{46}$ medium agar at $\sim 60^{\circ} \mathrm{C}$ was added on the top of the spores on the coverslip to form an agar pad with a thickness of $\sim 3 \mathrm{~mm}$. Some agar on the side of the pad was removed to form a small hole which contained air and then a second coverslip was applied to seal the top of the agar pad thus preparing the spores for DIC or bright-field microscopy, as described above. A digital CCD camera (12 bits, 1392 by 1040 pixels) was used to record the bright-field images of the spores on the coverslip at a rate of 1 frame every $15 \mathrm{~s}$ or $60 \mathrm{~s}$ for 4 to $15 \mathrm{~h}$. A home-made auto-focusing system was developed to lock-in the live-cell imaging in focus for more than $15 \mathrm{~h} .{ }^{44}$ These images were analyzed with a program written in Matlab as described above. In these measurements, the fates of $\geq 1000$ individual spores were monitored.

In order to measure the stress resistance of high vacuum-treated spores, untreated and high vacuum-treated spores were exposed to dry heat at $140^{\circ} \mathrm{C}$ for $7 \mathrm{~min}$ and then spore germination with $1 \mathrm{mM} \mathrm{L}$-valine and subsequent growth were analyzed on the LB medium agar pad as described above. The germination and subsequent growth of untreated and high vacuum-treated spores were also examined and analyzed on an LB medium agar pad with $1 \mathrm{M} \mathrm{NaCl}$ as described above.

\section{Statistical analyses}

For all germination experiments, $\geq 300$ spores were examined, and because of intrinsic heterogeneity of spore germination, significance analysis were not suitable for germination parameter values. For spore viability analyses on agar plates, three replicates were performed and statistical significance was analyzed using Student's $t$ test. With regards to spore germination, outgrowth, elongation, and vegetative growth, 5 images ( $\geq 1000$ spores) were examined.

\section{DATA AVAILABILITY}

All relevant data are available from the corresponding author.

\section{ACKNOWLEDGEMENTS}

S.W. and Y-.Q.L. received support from the National Natural Science Foundation of China (grant 31770152 to SW and grant 91751110 to YL). L.H. and S.W. received support through award XDA15007808 from the National Space Science Center of Chinese Academy of Sciences. L.H., S.W. and Y-.Q.L. received support from the high- level talent program of Dongguan University of Technology (KCYCXPT2017003). Y-.Q. L. and P.S. received funding support through award R21Al26067 from the National Institutes of Allergy and Infectious Diseases (NIAID). R.M. was supported by a grant from the German Aerospace Center (DLR-FuW-Projekt ISS LIFE, Programm RF-FuW, Teilprogramm 475). M.C. was supported by the doctoral scholarship DLR-DAAD no. 57370122. L.H. received support from the Guangdong Science and Technology Planning Program (grant No. 2017A010102019).

\section{AUTHOR CONTRIBUTIONS}

Conceptualization: Y-.Q.L., R.M., P.S.; Data curation: L.H., S.W., M.C., M.W.; Formal analysis: L.H., S.W., M.C., M.W.; Funding acquisition: Y-.Q.L., R.M., P.S., L.H., S.W., M.C.; Investigation: Y-.Q.L., R.M., P.S.; Methodology: L.H., S.W., M.C., M.W., Y-.Q.L., R.M., P.S.; Project administration: Y-.Q.L.; Resources: Y-.Q.L., R.M.; Supervision: Y-.Q.L., R.M., P.S.; Writing-original draft: S.W., Y-.Q.L., R.M., P.S.; Writing一review and editing: S.W., Y-.Q. L., R.M., P.S..

\section{ADDITIONAL INFORMATION}

Supplementary information accompanies the paper on the npj Microgravity website (https://doi.org/10.1038/s41526-018-0059-7).

Competing interests: The authors declare no competing interests.

Publisher's note: Springer Nature remains neutral with regard to jurisdictional claims in published maps and institutional affiliations.

\section{REFERENCES}

1. Horneck, G., Klaus, D. M. \& Mancinelli, R. L. Space microbiology. Microbiol. Mol. Biol. Rev. 74, 121-156 (2010).

2. Nicholson, W. L., Munakata, N., Horneck, G., Melosh, H. J. \& Setlow, P. Resistance of Bacillus endospores to extreme terrestrial and extraterrestrial environments. Microbiol. Mol. Biol. Rev. 64, 548-572 (2000).

3. Stevenson, A. et al. Multiplication of microbes below 0.690 water activity: implications for terrestrial and extraterrestrial life. Environ. Microbiol. 17, 257-277 (2015).

4. Soper, C. J. \& Davies, D. J. The response of bacterial spores to vacuum treatments. I. Design and characterization of the vacuum apparatus. Cryobiol 13, 61-70 (1976).

5. Soper, C. J., Whistler, J. M. \& Davies, D. J. The response of bacterial spores to vacuum treatments. II. Germination and viability studies. Cryobiol 13, 71-79 (1976).

6. Horneck, G. Responses of Bacillus subtilis spores to space environment: results from experiments in space. Orig. Life Evol. Biosph. 23, 37-52 (1993).

7. Dose, K. \& Klein, A. Response of Bacillus subtilis spores to dehydration and UV irradiation at extremely low temperatures. Orig. Life Evol. Biosph. 26, 47-59 (1996).

8. Moeller, R. et al. Astrobiological aspects of the mutagenesis of cosmic radiation on bacterial spores. Astrobiol 10, 509-521 (2010).

9. Moeller, R., Reitz, G., Nicholson, W. L. \& Horneck, G. Mutagenesis in bacterial spores exposed to space and simulated martian conditions: data from the EXPOSE-E spaceflight experiment PROTECT. Astrobiol 12, 457-468 (2012).

10. Neuberger, K., Lux-Endrich, A., Panitz, C. \& Horneck, G. Survival of spores of Trichoderma longibrachiatum in space: data from the space experiment SPORES on EXPOSE-R. Int. J. Astrobiol. 14, 129-135 (2015).

11. Panitz, C. et al. The SPORES experiment of the EXPOSE-R mission: Bacillus subtilis spores in artificial meteorites. Int. J. Astrobiol. 14, 105-114 (2015).

12. Higgins, D. \& Dworkin, J. Recent progress in Bacillus subtilis sporulation. FEMS Microbiol. Rev. 36, 131-148 (2012).

13. Paredes-Sabja, D., Shen, A. \& Sorg, J. A. Clostridium difficile spore biology: sporulation, germination and spore structural proteins. Trends Microbiol. 22, 406-416 (2014).

14. Setlow, P. When the sleepers wake: the germination of spores of Bacillus species. J. Appl. Microbiol. 115, 1251-1268 (2013).

15. Tan, I. S. \& Ramamurthi, K. S. Spore formation in Bacillus subtilis. Environ. Microbiol. Rep. 6, 212-225 (2014).

16. Mallozzi, M., Viswanathan, V. K. \& Vedantam, G. Spore-forming Bacilli and Clostridia in human disease. Fut. Microbiol 5, 1109-1123 (2010).

17. Logan, N. A. Bacillus and relatives in foodborne illness. J. Appl. Microbiol 112, 417-429 (2012).

18. Setlow, P. \& Johnson, E.A. Spores and their significance. (eds Doyle, M., \& Beuchat, L.) Food microbiology: fundamentals and frontiers. 45-79 (ASM Press, Washington, DC, 2012). 
19. Dose, K., Bieger-Dose, A., Kerz, O. \& Gill, M. DNA-strand breaks limit survival in extreme dryness. Orig. Life Evol. Biosph. 21, 177-187 (1991).

20. Wang, G., Zhang, P., Setlow, P. \& Li, Y. Kinetics of germination of wet-heat-treated individual spores of Bacillus. Appl. Environ. Microbiol. 77, 3368-3379 (2011).

21. Wang, S., Doona, C. J., Setlow, P. \& Li, Y.-q Use of Raman spectroscopy and phasecontrast microscopy to characterize cold atmospheric plasma inactivation of individual bacterial spores. Appl. Environ. Microbiol. 82, 5775-5784 (2016).

22. Setlow, P. Germination of spores of Bacillus species: what we know and do not know. J. Bacteriol. 196, 1297-1305 (2014).

23. Setlow, P., Wang, S. \& Li, Y.-q Germination of spores of the orders Bacillales and Clostridiales. Annu. Rev. Microbiol. 71, 459-477 (2017).

24. Wang, S., Setlow, P. \& Li, Y.-q Slow leakage of Ca-dipicolinic acid from individual Bacillus spores during initiation of spore germination. J. Bacteriol. 197, 1095-1103 (2015).

25. Wang, S., Shen, A., Setlow, P. \& Li, Y.-q Characterization of the dynamic germination of individual Clostridium difficile spores using Raman spectroscopy and differential interference contrast microscopy. J. Bacteriol. 197, 2361-2373 (2015).

26. Hurst, A. Bacterial injury: a review. Can. J. Microbiol. 23, 935-944 (1977).

27. Bucker, H. \& Horneck, G. Survival of microorganisms under simulated space conditions. Life Sci. Space Res 8, 33-38 (1970).

28. Cortezzo, D. E., Koziol-Dube, K., Setlow, B. \& Setlow, P. Treatment with oxidizing agents damages the inner membrane of spores of Bacillus subtilis and sensitizes spores to subsequent stress. J. Appl. Microbiol. 97, 838-852 (2004).

29. Magge, A. et al. Role of dipicolinic acid in the germination, stability, and viability of spores of Bacillus subtilis. J. Bacteriol. 190, 4798-4807 (2008).

30. Dose, K. \& Gill, M. DNA stability and survival of Bacillus subtilis spores in extreme dryness. Orig. Life Evol. Biosph. 25, 277-293 (1995).

31. Bieger-Dose, A., Dose, K., Meffert, R., Mehler, M. \& Risi, S. Extreme dryness and DNA-protein cross-links. Adv. Space Res. 12, 265-270 (1992).

32. de Ory, A. et al. Identification of a conserved 5'-dRP lyase activity in bacterial DNA repair ligase $D$ and its potential role in base excision repair. Nucleic Acids Res $\mathbf{2 4 4}$ 1833-1844 (2016).

33. Moeller, R. et al. Resistance of Bacillus subtilis spore DNA to lethal ionizing radiation damage relies primarily on spore core components and DNA repair, with minor effects of oxygen radical detoxification. Appl. Environ. Microbiol. 80, 104-109 (2014)

34. Bagyan, I., Casillas-Martinez, L. \& Setlow, P. The katX gene, which codes for the catalase in spores of Bacillus subtilis, is a forespore-specific gene controlled by $\sigma^{F}$, and KatX is essential for hydrogen peroxide resistance of the germinating spore. J. Bacteriol. 180, 2057-2062 (1998).

35. He, L. et al. Germination, outgrowth and vegetative growth kinetics of dry heattreated individual spores of Bacillus species. Appl. Environ. Microbiol. 84 e02618-e02717 (2018).

36. Nicholson, W. L. \& Setlow, P. Sporulation, germination and outgrowth (eds Harwood, C. \& Cutting, A.) Molecular biological methods for Bacillus. 391-450 (John Wiley, Chichester, UK, 1990)..
37. Yi, X. \& Setlow, P. Studies of the commitment step in the germination of spores of Bacillus species. J. Bacteriol. 192, 3424-3433 (2010).

38. Kong, L. B., Zhang, P. F., Setlow, P. \& Li, Y. Q. Multifocus confocal Raman microspectroscopy for rapid single-particle analysis. J. Biomed. Opt. 16, 120503 (2011)

39. Kong, L. B., Setlow, P. \& Li, Y. Q. Analysis of the Raman spectra of $\mathrm{Ca}^{2+}$-dipicolinic acid alone and in the bacterial spore core in both aqueous and dehydrated environments. Analyst 137, 3683-3689 (2012).

40. Chen, D., Huang, S.-s \& Li, Y.-q Real-time detection of kinetic germination and heterogeneity of single Bacillus spores by laser tweezers Raman spectroscopy. Anal. Chem. 78, 6936-6941 (2006).

41. Huang, S.-s et al. Levels of Ca2 +-dipicolinic acid in individual Bacillus spores determined using microfluidic Raman tweezers. J. Bacteriol. 189, 4681-4687 (2007).

42. Kong, L. et al. Characterization of bacterial spore germination using phasecontrast and fluorescence microscopy, Raman spectroscopy and optical tweezers. Nat. Protoc. 6, 625-639 (2011).

43. Horneck, G., Stöffler, D., Eschweiler, U. \& Hornemann, U. Bacterial spores survive simulated meteorite impact. Icarus 149, 285-293 (2001).

44. Zhang, P., Kong, L., Wang, G., Setlow, P. \& Li, Y.-q Combination of Raman tweezers and quantitative differential interference contrast microscopy for measurement of dynamics and heterogeneity during the germination of individual bacterial spores. J. Biomed. Opt. 15, 056010-056019 (2010).

45. Zhang, P. et al. Factors affecting variability in time between addition of nutrient germinants and rapid dipicolinic acid release during germination of spores of Bacillus species. J. Bacteriol. 192, 3608-3619 (2010).

46. Miller, J. H Experiments in Molecular Genetics (Cold Spring Harbor Laboratory, New York, 1972) 431-432.

\section{(i)}

Open Access This article is licensed under a Creative Commons Attribution 4.0 International License, which permits use, sharing, adaptation, distribution and reproduction in any medium or format, as long as you give appropriate credit to the original author(s) and the source, provide a link to the Creative Commons license, and indicate if changes were made. The images or other third party material in this article are included in the article's Creative Commons license, unless indicated otherwise in a credit line to the material. If material is not included in the article's Creative Commons license and your intended use is not permitted by statutory regulation or exceeds the permitted use, you will need to obtain permission directly from the copyright holder. To view a copy of this license, visit http://creativecommons. org/licenses/by/4.0/.

(c) The Author(s) 2018 